\title{
Lack of significant effect of interleukin-18 gene variants on tuberculosis susceptibility in the Polish population
}

\author{
Sebastian Wawrocki ${ }^{\circledR}{ }^{\otimes}$, Grzegorz Kielnierowski², Wieslawa Rudnicka ${ }^{1}$ and \\ Magdalena Druszczynska'
}

1Department of Immunology and Infectious Biology, Institute of Microbiology, Biotechnology and Immunology, Faculty of Biology and Environmental Protection, University of Lodz, Łódź, Poland; ${ }^{2}$ Regional Specialized Hospital of Tuberculosis, Lung Diseases and Rehabilitation, Tuszyn, Poland

Background: Polymorphisms in genes encoding cytokines are known to determine susceptibility to Mycobacterium tuberculosis (M.tb) infection. In particular, interleukin-18 (IL-18), an inducer of interferon-gamma (IFN- $\gamma$ ), playing an important role in anti-mycobacterial immune responses, may influence the risk of developing active tuberculosis (TB). Aim: A case-control study was performed to investigate whether two promoter polymorphisms of the IL-18 gene at positions -137G/A (rs187238) and -607A/C (rs1946518) affect the serum level of IL-18 and might be associated with genetic susceptibility to tuberculosis (TB) in the Polish population. Methods: Two IL-18 gene promoter SNPs were detected by an allele-specific polymerase chain reaction. Serum IL-18 levels were measured immunoenzymatically using Human Total IL-18 ELISA DuoSet (R\&D). Results: A singlegene analysis showed no differences either in allele or genotype frequencies of the studied SNPs between TB patients and healthy controls. No significant differences in the frequencies of any of the haplotypes between TB patients and healthy controls were found. None of the polymorphic variants of IL-18(-137G/A) or IL-18(-607A/C) SNP was associated with IL-18 producing capability. Conclusion: Our results suggest that IL-18(-137G/A) and IL$18(-607 \mathrm{~A} / \mathrm{C})$ polymorphisms may not be risk factors for susceptibility to TB in the Polish population. Increased serum IL-18 level observed in TB patients has no genetic background, but is a consequence of M.tb infection. Further studies with a higher sample size are required to confirm these findings.

Key words: interleukin-18 (IL-18), tuberculosis, gene polymorphism

Received: 26 March, 2019; revised: 31 March, 2019; accepted: 22 June, 2019; available on-line: 09 July, 2019

$\bigotimes_{\text {e-mail: sebastian.wawrocki@biol.uni.lodz.pl }}$

Acknowledgments of Financial Support: This work was supported by the National Science Centre grants no. 2015/19/N/NZ6/01385 and 2016/21/B/NZ7/01771

Abbreviations: BCG vaccine, Bacillus Calmette-Guérin vaccine; M.tb, Mycobacterium tuberculosis; SNPs, single nucleotides polymorphisms; TB, tuberculosis

\section{INTRODUCTION}

Interactions between cytokines and their influence on the activity of the human immune system remain an important subject of many scientific studies (Etna et al., 2014; Sobti et al., 2011). Among the interlinking network of interactions between cytokines, one of the important nodes is interleukin 18 , belonging to the family of inter- leukin 1 and expressed by a range of inflammatory cell types. The protein, described for the first time in 1995 and named "IFN-gamma inducing factor", is a pleiotropic cytokine produced by various hematopoietic and nonhematopoietic cells. IL-18 takes part in a number of reactions in the human body and has countless roles ranging from its involvement in maintaining the homeostasis, through not always positive involvement in the development of autoimmune diseases, to a significant role in the prevention of infectious diseases such as tuberculosis (TB) and many others (Akdis et al., 2016; Dinarello et al., 2013; Wawrocki et al., 2016). Among numerous infectious diseases, pulmonary tuberculosis has been a serious health concern for many years, despite the large-scale prophylactic vaccination with the BCG vaccine (Bacillus Calmette-Guérin) introduced in 1921. A significant problem regarding the incidence of $\mathrm{TB}$ is co-infection with the HIV virus and a successive increase in the frequency of isolation of multi-drug resistant TB (MDR-TB). According to the latest data from the World Health Organization, approximately 1.7 billion people in the world are infected with Mycobacterium tuberculosis (M.tb). These infections usually take a latent form, however, in at least $10 \%$ of cases they can transform into the active form of the disease. This problem is growing due to the increasing number of people with immunodeficiencies such as patients with autoimmune diseases and cancers, who take immunosuppressive drugs, as well as elderly people who, because of their age, are at a higher risk of reactivation of the latent M.tb infection. The interactions between mycobacteria and the human body at the molecular and cellular levels are still poorly understood. Recent studies demonstrated the existence of polymorphisms within the regulatory sequences of the interleukin 18 gene, which is located at chromosome $11 \mathrm{q} 22.2-22.3$ position and consists of five introns and six exons. More specifically, several differences in single nucleotides can alter the way transcription factors are joined, thereby influencing the expression and the immunological activity of IL-18. SNP-type mutations in the -607C/A (rs1946518) and $-137 \mathrm{G} / \mathrm{C}$ (rs187238) positions of the IL-18 promoter region seem to be particularly interesting due to the fact that a change from cytosine to adenine at position -607 may negatively affect the transduction factor cAMP and activation of adenyl cyclase, while nucleotide change at position -137 involving the conversion of guanine into cytosine may influence the activity of the nuclear factor H4TF-1 and result in a potential decrease in gene expression (Giedraitis et al., 2001; Pawlik et al., 2009). As was shown, IL-18 deficiency increases the susceptibility to mycobacterial infection. Kinjo and others (Kinjo 
et al., 2002) demonstrated that IL-18 knockout mice, characterized by attenuated production of IFN- $\gamma$, were more prone to $M$.tb infection than wild-type individuals. Therefore, genetic variations within the IL-18 gene might potentially predispose to the development of TB in humans through their influence on the expression of the cytokine and, subsequently, IFN- $\gamma$-mediated Th1 response.

Single nucleotides polymorphisms (SNPs) in many cytokine-encoding genes are attributed to ethnicity and occur frequently in the Far East populations. Literature data on the occurrence of such SNPs among Caucasians is contradictory (Akdis et al., 2016; Giedraitis et al., 2001; Zhou et al., 2015). In our study, we tested the hypothesis whether two promoter polymorphisms of the IL-18 gene at positions $-137 \mathrm{G} / \mathrm{A}$ and $-607 \mathrm{~A} / \mathrm{C}$ might contribute to TB susceptibility in the Polish population. We compared the allele and genotype frequencies of polymorphic variants between TB patients and healthy controls as well as assessed their serum concentration of IL-18.

\section{MATERIALS AND METHODS}

Study subjects. A study group consisted of 192 HIVnegative adults vaccinated with $M$. bovis BCG including 68 patients with pulmonary tuberculosis (37 males, 31 females) aged 21-81 years hospitalized in the Regional Center Hospital for Tuberculosis, Lung Diseases and Rehabilitation in Lodz, Poland and 124 healthy volunteers (38 males, 86 females) aged 18-84 years, who had never had tuberculosis. TB diagnosis was established by ZiehlNeelsen staining of sputum smears and M.tb culture as well as chest radiography and standard clinical examination by infectious disease consultants. All subjects had given written informed consent to participate in the study, which was approved by the ethics committee. Blood samples obtained from the volunteers were used for DNA isolation and assessment of polymorphisms in the promoter region of the IL-18 gene, whereas serum was used to assess the level of IL-18 protein.

DNA isolation. Genetic material was isolated from 2 $\mathrm{ml}$ of peripheral blood obtained from all volunteers using EDTA tubes and the BD Vacutainer ${ }^{\circledR}$ Blood Collection system. DNA isolation was based on the use of a commercial QIAamp ${ }^{\circledR}$ DNA Blood Mini set and was carried out from the buffy coat obtained after centrifugation $\left(150 \times g, 4^{\circ} \mathrm{C}, 10 \mathrm{~min}\right)$. The isolation process was fully compliant with the manufacturer's guidelines enclosed in the kit's instructions and carried out within no more than 2 hours from the collection of the blood sample. The extracted DNA was stored at $-80^{\circ} \mathrm{C}$ until analyzed.

Quantification of serum IL-18 level. Serum in a volume of approximately $1 \mathrm{ml}$ was obtained from subjects using BD Vacutainer ${ }^{\circledR}$ Blood Collection system tubes and was used for evaluation of IL-18 protein level by Human Total IL-18 DuoSet ELISA (R\&D) according to the manufacturer's instructions.

IL-18 SNPs genotyping. Polymerase chain reactions (PCRs) were performed using the primers for 2 promoter SNPs: rs187238 (-137G/A) and rs1946518 (-607A/C). For -137G/A SNP: 5'CCCCAACGGAAGCT'T'T'TAAAAAG-3' (-137G allele-specific), 5'-CCCCAACGGAAGCT'T'TTAAAAAC-3' (-137A allelespecific) and 5'-AGGAGGTGCGCAAAAACTGG-3' (common reverse) primers were used to amplify a 261-bp product. A control primer 5'-CCAATACTGGGAAT'TATTCCGCA-3' and the same common re-
A

$-137 G / C$

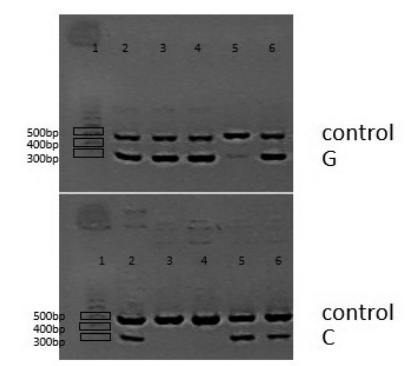

B

$-607 C / A$

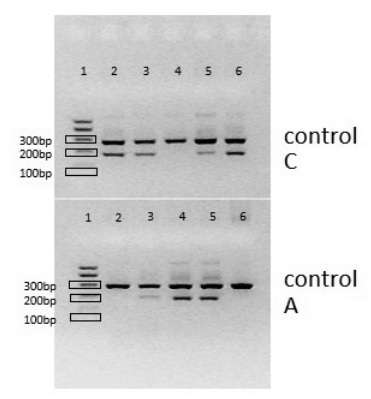

Figure 1. PCR products of $-137 \mathrm{G} / \mathrm{A}$ (A) and $-607 \mathrm{~A} / \mathrm{C}$ (B) SNPs visualized under UV light after staining with ethidium bromide. The electrophoresis was done on $2 \%$ agarose gel at 5 volt/cm for 2 hours. Lane 1: DNA molecular weight marker, lanes 2-6: samples.

verse primer were used to yield a 446-bp product as an internal positive amplification control (Fig. 1A). For -607A/C SNP: 5'-GT'TGAAGCAAGTGTAATTATTAAAAA-3' (-607A allele-specific), 5'-GCAGAAGTTAGTGTAAAAAT'TAT'TAC-3' (-607C allele-specific) and 5'-CCTTAACATCTTGGATCACC-3' (common reverse) primers were used to amplify a 196-bp product. A control primer 5'-CT'T'TGCCAT'TAT'TCCAGGAA-3' and the same common reverse primer were used to yield a 301-bp product as an internal positive amplification control (Fig. 1B) (Giedraitis, 2001). Reactions were performed in a Biometra PCR thermocycler using Bio-Rad reagents including iProof ${ }^{\text {TM }}$ High-Fidelity DNA Polymerase. At the first step, denaturation was performed for 2 min at $94^{\circ} \mathrm{C}$, followed by seven cycles of $94^{\circ} \mathrm{C}$ for $20 \mathrm{~s}, 64^{\circ} \mathrm{C}$ for $40 \mathrm{~s}$ and $72^{\circ} \mathrm{C}$ for $40 \mathrm{~s}$ and after that 25 cycles of $94^{\circ} \mathrm{C}$ for $20 \mathrm{~s}, 57^{\circ} \mathrm{C}$ for $40 \mathrm{~s}, 72^{\circ} \mathrm{C}$ for $40 \mathrm{~s}$. The PCR products were visualized by electrophoresis in a 2\% agarose gel stained with ethidium bromide using a documentation system Gel Doc 2000 (Bio-Rad).

Statistical analysis. Statistical analyses were done using Statistica 13.0 PL software (StatSoft, Poland). HardyWeinberg equilibrium (HWE) was tested using a webbased program (http://ihg2.helmholtz-muenchen.de/ cgi-bin/hw/hwa1.pl). Differences in allelic and genotypic frequencies between TB patients and healthy volunteers were compared by Pearson's chi-square test or two-tailed Fisher's exact tests when analyzing frequencies were lower than five to determine statistically significant differences between the studied groups. Odds ratios (OR) with the respective $95 \%$ confidence intervals (95\% CI) 
Table 1. Distribution of alleles and genotypes of the $-137 \mathrm{G} / \mathrm{C}$ polymorphism in the IL-18 gene

\begin{tabular}{|c|c|c|c|c|c|}
\hline$-137 \mathrm{G} / \mathrm{C}$ & & $\begin{array}{l}T B \\
n=68\end{array}$ & $\begin{array}{l}\mathrm{HC} \\
n=124\end{array}$ & OR $(95 \% \mathrm{Cl})$ & $p$ \\
\hline \multirow{2}{*}{ Allele } & G & $93(68 \%)$ & $172(69 \%)$ & \multirow{2}{*}{$0.96(0.61-1.50)$} & \multirow{2}{*}{0.84} \\
\hline & C & $43(32 \%)$ & $76(31 \%)$ & & \\
\hline \multirow{4}{*}{ Genotype } & $\mathrm{G} / \mathrm{G}$ & $32(47 \%)$ & $60(48 \%)$ & 1 & 0.86 \\
\hline & $\mathrm{G} / \mathrm{C}$ & $29(43 \%)$ & $52(42 \%)$ & $1.05(0.56-1.95)$ & 0.92 \\
\hline & $\mathrm{C} / \mathrm{C}$ & $7(10 \%)$ & $12(10 \%)$ & $1.09(0.39-3.05)$ & 0.89 \\
\hline & $\mathrm{p}^{\mathrm{HWE}}$ & 1.00 & 0.84 & & \\
\hline
\end{tabular}

Table 2. Distribution of alleles and genotypes of the $-607 \mathrm{C} / \mathrm{A}$ polymorphism in the IL-18 gene

\begin{tabular}{|c|c|c|c|c|c|}
\hline$-607 C / A$ & & $\begin{array}{l}T B \\
n=68\end{array}$ & $\begin{array}{l}\mathrm{HC} \\
n=124\end{array}$ & OR $(95 \% \mathrm{Cl})$ & $p$ \\
\hline \multirow{2}{*}{ Allele } & C & $89(65 \%)$ & $151(61 \%)$ & \multirow{2}{*}{$1.22(0.78-1.88)$} & \multirow{2}{*}{0.37} \\
\hline & A & $47(35 \%)$ & $97(39 \%)$ & & \\
\hline \multirow{4}{*}{ Genotype } & $\mathrm{C} / \mathrm{C}$ & $27(40 \%)$ & $42(34 \%)$ & 1 & 0.42 \\
\hline & $C / A$ & $35(51 \%)$ & $67(54 \%)$ & $0.81(0.43-1.53)$ & 0.73 \\
\hline & $\mathrm{A} / \mathrm{A}$ & $6(9 \%)$ & $15(12 \%)$ & $0.62(0.21-1.80)$ & 0.48 \\
\hline & $\mathrm{p}^{\mathrm{HWE}}$ & 0.42 & 0.19 & & \\
\hline
\end{tabular}

were also calculated. Probability values of 0.05 or less were regarded as statistically significant. Differences in serum IL-18 levels were analyzed using the Mann-Whitney U-test. The logistic regression analysis done for the important main and interaction effects was performed using the SNPstats software (http://bioinfo.iconcologia. net/SNPstats).

\section{RESULTS}

\section{Genotype and allele distribution of polymorphisms in the IL-18 promoter region among TB patients and healthy controls}

The distribution of IL-18-(137G/A)or IL-18(-607A/C) genotypes in TB and $\mathrm{HC}$ groups is shown in Tables 1 and 2. There was no evidence to reject the Hardy-Weinberg equilibrium (HWE) hypothesis in both TB and HC groups at the standard significance level of 0.05 .

The dominant homozygous G/G IL-18(-137G/C) genotype was the most frequent among the studied groups occurring in 47\% (32/68) TB patients and 48\% $(60 / 124)$ healthy volunteers (Table 2). The frequency of $\mathrm{G} / \mathrm{C}$ IL-18(-137G/C) genotype in the groups under study was also similar, at 43\% (29/43) among TB and $42 \%$ (52/124) among HC subjects. The C/CIL-18(-
$137 \mathrm{G} / \mathrm{C})$ genotype was equally uncommon $(10 \%)$ in TB and $\mathrm{HC}$ individuals (Table 1 ).

Similarly to IL-18(-137G/C) genotypes, IL-18($607 \mathrm{C} / \mathrm{A})$ gene variants were comparatively distributed among $\mathrm{TB}$ and $\mathrm{HC}$ groups (Table 2). The heterozygous C/A IL-18(-607C/A) genotype was found in 51\% (35/67) patients with TB and $54 \%(67 / 124)$ healthy controls, whereas C/C IL-18(-607C/A) homozygosity occurred in 40\% (27/68) TB patients and 34\% (42/124) healthy individuals. The least frequent genotype was the A/A IL-18(-607C/A) variant (Table 2).

\section{Haplotype frequencies analysis}

A pair-wise nucleotide analysis revealed no significant differences in the frequencies of four haplotypes between TB patients and healthy controls (Table 3). The "CG" haplotype was the most common in both studied groups, occurring in $60.6 \%$ of TB patients and $57.6 \%$ of healthy controls. The rarest "CC" haplotype was found in $4.8 \%$ of TB patients and $3.2 \%$ of healthy individuals (Table 3).

\section{Effect of IL-18 gene polymorphism on serum IL-18 level}

Statistical analysis of the serum IL-18 levels in the studied groups showed a significantly higher concentration of IL-18 among TB patients (880.2 $\pm 1079.1 \mathrm{pg} /$ $\mathrm{ml})$ compared to healthy controls $(467.4 \pm 462.4 \mathrm{pg} / \mathrm{ml})$

Table 3. Results of the IL-18 haplotype analysis in the studied population.

\begin{tabular}{|c|c|c|c|c|c|c|c|}
\hline \multirow{3}{*}{ Haplotype } & \multicolumn{2}{|l|}{ IL-18 SNP } & \multicolumn{5}{|c|}{ Haplotype statistics } \\
\hline & \multirow{2}{*}{$-607 C / A$} & \multirow{2}{*}{$-137 \mathrm{G} / \mathrm{C}$} & \multicolumn{3}{|c|}{ Frequency (\%) } & \multirow{2}{*}{ OR $(95 \% \mathrm{Cl})$} & \multirow{2}{*}{$p$-value } \\
\hline & & & Total & TB patients & Healthy controls & & \\
\hline 1 & C & G & 58.7 & 60.6 & 57.6 & 1.00 & - \\
\hline 2 & A & C & 27.2 & 26.8 & 27.4 & $0.89(0.54-1.47)$ & 0.65 \\
\hline 3 & A & G & 10.3 & 7.7 & 11.6 & $0.58(0.25-1.34)$ & 0.20 \\
\hline 4 & C & C & 3.8 & 4.8 & 3.2 & $1.44(0.45-4.58)$ & 0.54 \\
\hline
\end{tabular}


Table 4. Effect of IL-18 gene promoter -137G/C and -607C/A polymorphisms on serum IL-18 level.

\begin{tabular}{|c|c|c|c|c|}
\hline \multirow[b]{2}{*}{ SNP } & & \multicolumn{2}{|l|}{ IL-18 [pg/ml] } & \multirow[b]{2}{*}{$p$} \\
\hline & & $\begin{array}{l}\text { TB } \\
n=68\end{array}$ & $\begin{array}{l}\mathrm{HC} \\
\mathrm{n}=124\end{array}$ & \\
\hline \multicolumn{5}{|c|}{ IL-18 -137G/C } \\
\hline \multirow{3}{*}{ Genotype } & $\mathrm{G} / \mathrm{G}$ & $835.3 \pm 1321.3$ & $434.7 \pm 318.4$ & $p=0.02$ \\
\hline & $\mathrm{G} / \mathrm{C}$ & $874.3 \pm 618.2$ & $477.9 \pm 572.8$ & $p<0.001$ \\
\hline & $\mathrm{C} / \mathrm{C}$ & $1100.3 \pm 1458.0$ & $584.9 \pm 551.9$ & $p=0.43$ \\
\hline \multicolumn{5}{|c|}{ IL-18-607C/A } \\
\hline \multirow{3}{*}{ Genotype } & $\mathrm{C} / \mathrm{C}$ & $901.1 \pm 1429.2$ & $434.2 \pm 296.0$ & $p=0.03$ \\
\hline & $C / A$ & $822.5 \pm 762.5$ & $415.0 \pm 329.1$ & $p<0.001$ \\
\hline & $A / A$ & $1123.0 \pm 964.1$ & $793.9 \pm 990.5$ & $p=0.30$ \\
\hline
\end{tabular}

$(p<0001)$. Our results showed higher IL-18 levels in the sera from homozygous $-137 \mathrm{C} / \mathrm{C}$ and $-607 \mathrm{~A} / \mathrm{A}$ carriers from both groups when compared to the concentrations in the sera from the other individuals, however, the observed differences were not statistically significant $(p>0.05)$ (Table 4).

\section{DISCUSSION}

Most of the scientific reports in the past focused mainly on pathogen-host interactions, attributing an increase in susceptibility to the misfortune and unique features of the pathogen. Genetic factors and predispositions were closely related only to such diseases as cancer and cardiovascular diseases, and no one linked them to infectious diseases. Today, we know that these assumptions were not correct, studies from the late ' 80 s clearly showed that the genetic background can be even more important in the development of infectious diseases than in the cardiovascular disabilities (Möller \& Hoal, 2010).

The best way to determine human susceptibility to infectious diseases is a comprehensive analysis of the genome through a large-scale sequencing of the genetic material from many cases and controls. This method has many advantages and allows tracing any potential mutations and genetic changes affecting the incidence of disease. However, this approach has also many drawbacks such as high cost and potential difficulties in analyzing a huge amount of data representative for all the world's populations (Möller \& Hoal, 2010; Hirschhorn \& Daly, 2005).

After finding the evidence for linking the selected genome region to the susceptibility to the disease, genetic and physical maps are created based on the case studied to narrow the chromosome interval and allow gene identification or positional cloning in complex diseases where the function of the involved gene is not exactly known nor well described. In the case of pulmonary TB, recent linkage studies described many chromosomal regions which contain some genetic variations that affect the susceptibility of specific populations to the disease. This is worth emphasizing because the research units were most often able to find the characteristic variations only for a given group. Valuable scientific research and literature reports concerning susceptibility to pulmonary TB include: study on the population of Gambia and South Africa indicating the chromosome regions $15 q$ and $\mathrm{Xq}$ described by Bellamy and others in 2000 (Bellamy et al., 2000), analysis of patients from Morocco and the 8q12-q13 chromosomal region described by Bagh- dadi and others in 2006 (Baghdadi et al., 2006) or the Thai population described by Mahasirimongkol in 2009 (Mahasirimongkol, 2009) with the 5q23.2-q31.3 region and many others. These experiments were also based on the evaluation of many other parameters and diagnostic tests. What is worth pointing out is the fact that all the mentioned research papers described different regions of the human genome. The observed lack of similarity in the occurrence of susceptibility regions in these studies is probably due to the combination of many factors. Moreover, the sought-after genetic markers of susceptibility to TB are unique to a specific family or population, making them impossible to be confirmed in the studies on other populations. This confirms the thesis that this type of approach is possible only through a large financial outlay and examination of a very large group consisting of TB patients and healthy controls from numerous populations. Therefore, it seems more practical to focus on one selected gene whose expression corresponds, for example, to the production of a selected cytokine or which is known for its involvement in the development of the studied disease such as TB. This approach allows the assessment of susceptibility and focusing only on the key elements associated with the development of disease and immunity. A significant role is played by the occurrence of SNP-type mutations in genes of cytokines directly related to the development of TB. IFN- $\gamma$, encoded by the IFNG gene, is secreted by Th1 cells as the main cytokine, which activates macrophages and is critical for controlling the development of M.tb infection. Epidemiological studies, including extensive meta-analysis, suggest links between IFNG polymorphism at $+874 \mathrm{~T} / \mathrm{A}$ (rs2430561) position and TB development. IFNG polymorphism is the most common studied polymorphism in terms of TB susceptibility, sites, and severity, however, those associations are still the subject of research due to population differences (Baghdadi et al., 2006; Bellamy et al., 2000; Hashemi et al., 2011; Mahasirimongkol et al., 2006; Shen et al., 2017; Wei et al., 2017). Other cytokine polymorphisms determining the outcome of $M . t b$ infection are located in genes encoding TNF- $\alpha$ (-308G/A, $-863 \mathrm{C} / \mathrm{A},-857 \mathrm{C} / \mathrm{T}$ and $-238 \mathrm{G} / \mathrm{A})$, IL-12 (641A/G, $684 \mathrm{C} / \mathrm{T}, 1094 \mathrm{~T} / \mathrm{C}$, and $1132 \mathrm{G} / \mathrm{C})$ and IL-10 (-1082G/ A, -819T/C, and -592A/C) (Fol et al., 2015; Han et al., 2011; Kim et al., 2012; Liang et al., 2014; Yi et al., 2015). In our study, we assessed the frequency of two polymorphic variants $(-137 \mathrm{G} / \mathrm{C}$ and $-607 \mathrm{C} / \mathrm{A})$ in the promoter of gene encoding IL-18, the most powerful inducer of IFN- $\gamma$. The polymorphism at position -137 was described by Giedraitis and others in 2001 (Giedraitis et al., 
2001), who showed that the occurrence of dominant homozygous genotypes resulted in an increase in TB incidence up to 1.6 times. Our observations did not confirm these results. Although the dominant homozygous IL-18$137 \mathrm{G} / \mathrm{G}$ genotype was the most frequent in the whole population, there was no difference in the frequency of the genotype occurrence among TB patients (47\%) and healthy controls $(48 \%)$. Interestingly, the percentage of the IL-18-137G allele in the Polish population (68.5\%) was found to be lower than that in the Chinese Han population $(86 \%)$. The diversity of the allele distribution may partially explain the differences in TB susceptibility between races. Two other polymorphic variants - IL18-137G/C and IL-18-137C/C were distributed similarly among the studied groups of Poles. All these data suggest that IL-18(-137G/C) SNP does not contribute to TB susceptibility in the Polish population. Similarly, the results by Zhou and others (Zhou et al., 2015) did not show any significant differences in the distribution of the $\mathrm{C} / \mathrm{C}(-137 \mathrm{G} / \mathrm{C})$ genotype, however, the frequency of the $\mathrm{G} / \mathrm{G}(-137 \mathrm{G} / \mathrm{C})$ genotype among the Chinese was significantly higher in the TB group than in the healthy control group. The authors suggested that the IL-18$137 \mathrm{G}$ allele might be a predisposing gene of TB, while the IL-18-137C allele played a role in preventing M.tb infection. The explanation for these discrepancies is difficult to find. Identified cytokine polymorphisms might be population-specific and associated with the resistance to mycobacterial infection in some but not all world's populations suggesting that they may serve as markers of TB susceptibility only in specific ethnic groups (Delgado et al., 2002; Zhou et al., 2015).

In our study, neither genotypes nor allele frequencies of IL-18(-607C/A) SNP showed differences between TB patients and healthy controls. These observations are consistent with the results obtained by Harishankar and others, Taheri and others and Zhou and others in the South India, Southeast Iran, and Chinese Han populations (Harishankar et al., 2007; Taheri et al., 2012; Zhou et al., 2015). The proportion of the IL-18-607C allele in the Polish population (63\%) is similar to that observed among the Iranians $(58.8 \%)$ or the Chinese $(53.3 \%)$.

To assess the effects of the IL-18 gene promoter SNPs on the expression of IL-18 protein and, consequently, on TB susceptibility, we measured IL-18 levels in the sera from the studied individuals. Our data did not confirm any effect of either IL-18-(137G/C) or IL$18(-607 \mathrm{C} / \mathrm{A})$ polymorphisms on IL-18 producing capability. Serum levels of IL-18 from each of the carriers were similar, however, in the group of TB patients, the observed concentrations of the cytokine were significantly higher than those measured for the controls. It indicates that the increase in the serum IL-18 level observed in TB patients has no genetic background, but is probably a consequence of M.tb infection. Lack of association between serum IL-18 concentrations and the IL-18 genotype was also observed by Evans and others (Evans et al., 2007). On the contrary, Zhouand others (Zhou et al., 2015) demonstrated that IL-18-137G/C polymorphism influenced the production of IL-18 by peripheral blood mononuclear cells (PBMCs) and showed that PBMCs from IL-18-137C/C individuals produced higher levels of IL-18 than those with the IL-18-137G/G genotype. Several studies also reported that alleles of the IL-18(607C/A) SNP are associated with different promoter activity of the IL-18 gene (Sivalingam et al., 2003; Takada et al., 2002). An example of such research is the study by Takada and co-workers, who demonstrated that in the Japanese population the $\mathrm{C}$ allele was correlated with the greater transcriptional activity of the IL-18 promoter resulting in the higher expression of IL-18 (Takada et al., 2002). However, our results are contradictory to those reporting such a relationship. The discrepancies could be due to many reasons. First of all, a low sample size of our study could have resulted in the limited power of detection of the studied genetic effect. Secondly, it is possible that the studied SNPs do not determine disease susceptibility directly, but are in linkage disequilibrium with other functional but so far unknown alleles. Finally, the differences in SNP-associated susceptibility may be ethnicity-related and present in specific populations all over the world.

In summary, our results suggest that IL-18(-137G/A) and IL-18(-607A/C) polymorphisms may not be the risk factors for susceptibility to TB in the Polish population. It will be utmost interesting to validate these findings with a higher sample size and to perform functional studies assessing the transcriptional activity of the IL-18 gene.

\section{Conflict of interest}

The authors declare that there is no conflict of interest regarding the publication of this article.

\section{REFERENCES}

Akdis M, Aab A, Altunbulakli C, Azkur K, Costa RA, Crameri R, Duan S, Eiwegger T, Eljaszewicz A, Ferstl R, Frei R, Garbani M, Globinska A, Hess L, Huitema C, Kubo T, Komlosi Z, Konieczna P, Kovacs N, Kucuksezer UC, Meyer N, Morita H, Olzhausen J, O’Mahony L, Pezer M, Prati M, Rebane A, Rhyner C, Rinaldi A, Sokolowska M, Stanic B, Sugita K, Treis A, van de Veen W, Wanke K, Wawrzyniak M, Wawrzyniak P, Wirz OF, Zakzuk JS, Akdis CA (2016) Interleukins (from IL-1 to IL-38), interferons, transforming growth factor $\beta$, and TNF- $\alpha$ : Receptors, functions, and roles in diseases. J. Allergy Clin. Immunol. 138: 984-1010. https://doi. org/10.1016/j.jaci.2016.06.033

Baghdadi J El, Orlova M, Alter A, Ranque B, Chentoufi M, Lazrak F, Archane MI, Casanova J-L, Benslimane A, Schurr E, Abel L (2006) An autosomal dominant major gene confers predisposition to pulmonary tuberculosis in adults. J. Exp. Med. 203: 1679-1684. https://doi.org/10.1084/jem.20060269

Bellamy R, Beyers N, McAdam KPWJ, Ruwende C, Gie R, Samaai P, Bester D, Meyer M, Corrah T, Collin M, Camidge DR, Wilkinson D, Hoal-van Helden E, Whittle HC, Amos W, van Helden P, Hill AVS (2000) Genetic susceptibility to tuberculosis in Africans: A genome-wide scan. Proc. Natl. Acad. Sci. 97: 8005-8009. https://doi. org/10.1073/pnas.140201897

Delgado JC, Baena A, Thim S, Goldfeld AE (2002) Ethnic-specific genetic associations with pulmonary tuberculosis. J. Infect. Dis. 186: 1463-1468. https://doi.org/10.1086/344891

Dinarello CA, Novick D, Kim S, Kaplanski G (2013) Interleukin-18 and IL-18 binding protein. Front. Immunol. 4: 1-10. https://doi. org/10.3389/fimmu.2013.00289

Etna MP, Giacomini E, Severa M, Coccia EM (2014) Pro-and antiinflammatory cytokines in tuberculosis: A two-edged sword in TB pathogenesis. Semin. Immunol. 26: 543-551. https://doi. org/10.1016/j.smim.2014.09.011

Evans J, Collins M, Jennings C, van der Merwe L, Söderström I, Olsson T, Levitt NS, Lambert E V, Goedecke JH (2007) The association of interleukin-18 genotype and serum levels with metabolic risk factors for cardiovascular disease. Eur. J. Endocrinol. 157: 633-640. https://doi.org/10.1530/EJE-07-0463

Fol M, Druszczynska M, Wlodarczyk M, Ograczyk E, Rudnicka W (2015) Immune response gene polymorphisms in tuberculosis. Acta Biochim. Pol. 62: 633-640. https://doi.org/10.18388/abp.2015_1130

Giedraitis V, He B, Huang W-X, Hillert J (2001) Cloning and mutation analysis of the human IL-18 promoter: a possible role of polymorphisms in expression regulation. J. Neuroimmunol. 112: 146-152. https://doi.org/10.1016/S0165-5728(00)00407-0

Han M, Yue J, Lian Y, Zhao Y, Wang H, Liu L (2011) Relationship between single nucleotide polymorphism of interleukin-18 and susceptibility to pulmonary tuberculosis in the Chinese Han population. Microbiol. Immunol. 55: 388-393. https://doi.org/10.1111/j.13480421.2011.00332.x

Harishankar M, Selvaraj P, Rajeswari DN, Anand SP, Narayanan PR (2007) Promoter polymorphism of IL-18 gene in pulmonary tuber- 
culosis in South Indian population. Int. J. Immunogenet. 34: 317-320. https:/ / doi.org/10.1111/j.1744-313X.2007.00714.x

Hashemi M, Sharifi-Mood B, Nezamdoost M, Moazeni-Roodi A, Naderi M, Kouhpayeh H, Taheri M, Ghavami S (2011) Functional polymorphism of interferon- $\gamma$ (IFN- $\gamma$ ) gene $+874 \mathrm{~T} / \mathrm{A}$ polymorphism is associated with pulmonary tuberculosis in Zahedan, Southeast Iran. Prague Med. Rep. 112: 38-43

Hirschhorn JN, Daly MJ (2005) Genome-wide association studies for common diseases and complex traits. Nat. Rev. Genet. 6: 95-108. https://doi.org/10.1038/nrg1521

Kim H-L, Cho SO, Kim S-Y, Kim S-H, Chung W-S, Chung S-H, Kim S-S, Ko S-G, Jeong C-H, Kim S-J, Hong S-H, Um J-Y (2012) Association of interleukin-18 gene polymorphism with body mass index in women. Reprod. Biol. Endocrinol. 10: 31. https://doi. org/10.1186/1477-7827-10-31

Kinjo Y, Kawakami K, Uezu K, Yara S, Miyagi K, Koguchi Y, Hoshino T, Okamoto M, Kawase Y, Yokota K, Yoshino K, Takeda K, Akira S, Saito A (2002) Contribution of IL-18 to Th1 response and host defense against infection by Mycobacterium tuberculosis: a comparative study with IL-12p40. J. Immunol. 169: 323-329

Liang B, Guo Y, Li Y, Kong H (2014) Association between IL-10 gene polymorphisms and susceptibility of tuberculosis: Evidence based on a meta-analysis. PLoS One 9: e88448. https://doi.org/10.1371/ journal.pone.0088448

Mahasirimongkol S, Chantratita W, Promso S, Pasomsab E, Jinawath N, Jongjaroenprasert W, Lulitanond V, Krittayapoositpot P, Tongsima S, Sawanpanyalert P, Kamatani N, Nakamura Y, Sura T (2006) Similarity of the allele frequency and linkage disequilibrium pattern of single nucleotide polymorphisms in drug-related gene loci between Thai and northern East Asian populations: implications for tagging SNP selection in Thais. J. Hum. Genet. 51: 896-904. https:// doi.org/10.1007/s10038-006-0041-1

Möller M, Hoal EG (2010) Current findings, challenges and novel approaches in human genetic susceptibility to tuberculosis. Tuberculosis 90: 71-83. https://doi.org/10.1016/j.tube.2010.02.002

Pawlik A, Kurzawski M, Drozdzik M, Dziedziejko V, Safranow K, Herczynska M (2009) Interleukin-18 gene (IL18) promoter polymorphisms in patients with rheumatoid arthritis. Scand. J. Rheumatol. 38: 159-165. https://doi.org/10.1080/03009740802600748
Shen L, Liang Z, Xu C, Yang J, Han X, Zhao H, Liu A, Bao F (2017) Association between interleukin-18-137G/C gene polymorphisms and tuberculosis risk in chinese population: A meta-analysis. J. Clin. Cell. Immunol. 08: 1-5. https://doi.org/10.4172/2155-9899.1000514

Sivalingam SP, Yoon KH, Koh DR, Fong KY (2003) Single-nucleotide polymorphisms of the interleukin-18 gene promoter region in rheumatoid arthritis patients: protective effect of AA genotype. Tissue Antigens 62: 498-504.

Sobti R, Sharma V, Abitew A, Berhane N, Mahdi S, Askari M, Kuttiat V, Wanchu A (2011) IL-18 Gene promoter region $607 \mathrm{C} / \mathrm{A}$ polymorphism in HIV-1 infected north indian population. Balk. J. Med. Genet. 14: 41-8. https://doi.org/10.2478/v10034-011-0046-8

Taheri M, Hashemi-Shahri SM, Hamzehnejadi M, Naderi M, MoazeniRoodi A, Bahari G, Hashemi M (2012) Lack of association between interleukin-18 -607 C/A gene polymorphism and pulmonary tuberculosis in Zahedan, Southeast Iran. Prague Med. Rep. 113: 16-22. https://doi.org/10.14712/23362936.2015.33

Takada T, Suzuki E, Morohashi K, Gejyo F (2002) Association of single nucleotide polymorphisms in the IL-18 gene with sarcoidosis in a Japanese population. Tissue Antigens 60: 36-42. https://doi. org/10.1034/j.1399-0039.2002.600105.x

Wawrocki S, Druszczynska M, Kowalewicz-Kulbat M, Rudnicka W (2016) Interleukin 18 (IL-18) as a target for immune intervention. Acta Biochim. Pol. 63: https://doi.org/10.18388/abp.2015_1153

Wei Z, Wenhao S, Yuanyuan M, Yang L, Daming Z, Jiangchun X, Jijun J (2017) A single nucleotide polymorphism in the interferon- $\gamma$ gene (IFNG $+874 \mathrm{~T} / \mathrm{A}$ ) is associated with susceptibility to tuberculosis. Oncotarget 8: 50415-50429. https://doi.org/10.18632/oncotarget. 17304

Yi Y-X, Han J-B, Zhao L, Fang Y, Zhang Y-F, Zhou G-Y (2015) Tumor necrosis factor alpha gene polymorphism contributes to pulmonary tuberculosis susceptibility: evidence from a meta-analysis. Int. J. Clin. Exp. Med. 8: 20690-20700

Zhou C, Ouyang N, Li QH, Luo SX, He Q, Lei H, Liu Q (2015) The $-137 \mathrm{G} / \mathrm{C}$ single nucleotide polymorphism in IL-18 gene promoter contributes to tuberculosis susceptibility in Chinese Han population. Infect. Genet. Evol. 36: 376-380. https://doi.org/10.1016/j. meegid.2015.10.014 